Review Article

www.ijrap.net

\title{
IPOMEA RENIFORMIS: A REVIEW OF ITS ETHNOMEDICINAL USES, PHYTOCHEMISTRY
} AND PHARMACOLOGY

Thakare C. V. ${ }^{1 *}$, Upasani C. D. ${ }^{2}$, Poul B. N. ${ }^{3}$, Patil S. S. ${ }^{4}$, Usnale S. V. ${ }^{5}$

${ }^{1}$ Lecturer, Maharashtra Poly (D. Pharmacy) Institute, Nilanga, Dist. Latur, Maharashtra, India

${ }^{2}$ Principal, Shri Sureshdada Jain College of Pharmacy, Tq. Chandwad Dist. Nasik, Maharashtra, India

${ }^{3}$ Principal, Maharashtra Poly (D. Pharmacy) Institute, Nilanga Dist. Latur, Maharashtra, India

${ }^{4}$ Professor, Maharashtra College of Pharmacy, Nilanga Dist. Latur, Maharashtra, India

${ }^{5}$ Assistant Professor, Maharashtra College of Pharmacy, Nilanga Dist. Latur, Maharashtra, India

Received on: 14/09/14 Revised on: 21/10/14 Accepted on: 14/11/14

\author{
*Corresponding author \\ Mr. C. V. Thakare, Lecturer, Maharshtra Polytechnic (D. Pharmacy) Institute, Nilanga Dist. Latur, Maharashtra 413521 India \\ E-mail: thakarecv15480@gmail.com
}

DOI: $10.7897 / 2277-4343.056134$

\begin{abstract}
Traditional medicine forms an integral part of health care system in many countries. According to WHO statistics, about $25 \%$ of the preserved human medicine are derived from plants, either their direct part is useful or their secondary metabolites are of prime importance. $80 \%$ people still depend upon traditional system of medicine. The practice of traditional medicines is based on hundreds of years of belief and observation, which exist before the development of the modern medicine. The knowledge of traditional medicine put the light on the discovery of new and potent medicine. Traditional medicine plays an important role in the health care of India. Scientifically sound data are lacking for many medicinal plants in India. Ipomea reniformis is a perennial plant having therapeutic and potential use. It is widely distributed all over the India in damp places. It is hidden from the eyes of the researchers and botanist. Literature of plant showed different pharmacological activity in animal study like antihypertensive, arthritis, analgesic, anti-inflammatory, antidiabetic, anticancer activity. This study supports the traditionally claimed medicinal activity. Activity of plant may be due to presence of phytoconstituents hence further studies are essential for chemical characterization of active principles and more extensive biological evaluation. I. reniformis was studied for its traditionally claimed activity but still traditionally claimed therapeutic potential of plant is required to study. Hence I. reniformis can be further explored for the study of traditionally claimed unexplored activities as well as isolation and identification of active constituents and to confirm exact mechanism of action.

Keywords: Ipomea reniformis, traditional use, secondary metabolites
\end{abstract}

\section{INTRODUCTION}

Traditional medicine forms an integral part of health care system in many countries. According to WHO statistics, about $25 \%$ of the preserved human medicine are derived from plants, either their direct part is useful or their secondary metabolites are of prime importance ${ }^{1,2} .80 \%$ people still depend upon traditional system of medicines for their primary health care needs. Herbal medicines can be defined as those products derived from any part of plant for the therapeutic use ${ }^{7}$. The practice of traditional medicines is based on hundreds of years of belief and observation, which exist before the development of the modern medicine. In some countries traditional medicine remains as an integral part of the formal health system and exist on an equal footing with current therapy. The global demand for herbal medicine is not only large, but also growing ${ }^{8}$. Approximately one-third of the top-selling drugs in the world are natural products or their derivatives often with ethno pharmacological background ${ }^{9}$. The ethno botanical research still plays its marked scientific role in stimulating further phytochemical and pharmacological studies ${ }^{10}$. The world health organisation is now actively focusing on developing countries to encourage them to use herbal medicine, which they have been traditionally used for centuries. Approximately 10-15\% of roughly 300000 species of higher plants have been used in traditional medicine system from last several years, as they are transferred from generation to generation. India is extremely rich source of medicinal plants comprising about 8000 species $^{11}$. This is due to the wide diversity of climatic conditions available in India, ranging from desert to swap lands. Many plants are known for their medicinal use. Traditional medicine plays an important role in the health care of India. Scientifically sound data are lacking for many medicinal plants in India. Natural products used in traditional herbal medicine can important source for search of novel medicinal compounds ${ }^{12}$. Over the last few years, researchers have aimed at identifying and validating plant derived substances for the treatment of various diseases. There are several reasons for the adaptation of natural and traditional medicine, as these are useful without or less side effect and contraindication ${ }^{13-15}$. The herbal medicine is not only used from recent time but it has been frequently used since the last thousands of years $^{16}$. Several examples of plant extracts being more efficacious, free from undesirable side effects as compared to their principle revalidated the therapeutic benefits of herbs due to totality of constituents rather than single molecule ${ }^{17}$. The medicinal plants produce wide range array of bioactive molecules and rich source of medicines ${ }^{18}$. The knowledge of traditional medicine put the light on the discovery of new and potent medicine. The benefit of ethnic knowledge can be harnessed and improved upon by its appropriate use, establishing validity of such knowledge and incorporating it with health care programme. Ipomea reniformis (I. reniformis) Family- convolvulaceae is a perennial, much branched herb having therapeutic and potential use. I. reniformis is also known as Merremia emarginata ( $M$. emarginata) Burm $^{19,20}$. It is hidden from the eyes of the researchers 
and botanist. Present review focus upon on the exploration of $I$. reniformis plant knowledge.

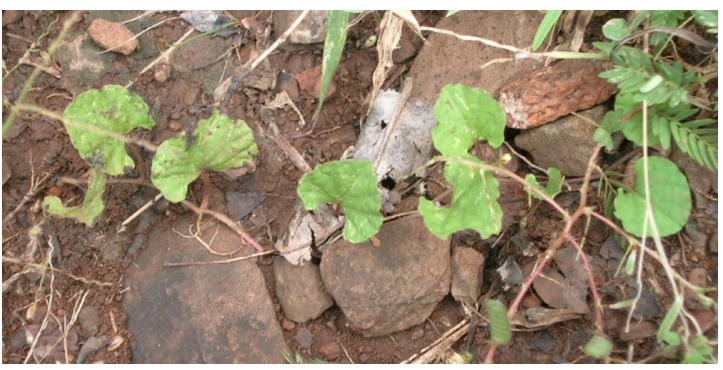

Figure: Ipomea reniformis ${ }^{21}$

\section{Taxonomy}

Kingdom- Plantae

Order- Solanales

Family- Convolvulaceae

Genus- Ipomea/ Merremia

Species- Ipomea reniformis/ Merremia emarginata ${ }^{22}$

\section{Local Names}

Bengal- undirakanipana; Bombay- undirkani; GujaratiUndarkani; Hindi- Musakani; Chennai- Yellikkadukirai; Sanskrit- Adibhu, Akhukarni, Bahukarnika, bahupadika, Bhudharashraya, bhumichari, Chanda, Chitra, Krishika, Mushakparni, Mushakarni, Mushikavhaya, parnika, Patrashreni, Phanjipatrika, pratiparnashipa, Putrashreni, Shatamulika, Sukarnika, Suvarni, undurkarni, Upchitra; Tamil- Perettaikkiray; Telugu- Toinnuatali; UrduChukakani $^{19,23}$.

\section{Habitat and Distribution}

It is widely distributed all over the India, especially in damp places in upper gigantic plain, Gujarat, Bihar, West Bengal, Western-Ghats, ascending up to $900 \mathrm{~m}$ in the hills, Goa, Karnataka in India, Ceylon and Tropical Africa $^{19,24}$.

\section{Botanical Description}

Stems numerous, filiform, creeping and rooting at the nodes, not twining, clothed with scattered long soft hairs. The leaves are simple, thin and reniform with entire margin having auriculate base and retuse apex. The size varies from $2-3 \mathrm{~cm}$ in length and width, petiolule $2-5 \mathrm{~cm}$ long. The leaf is bitter in taste, green in colour and with characteristic odour ${ }^{19,25}$.

\section{Useful Parts of Plant}

Every part of plant possesses some medicinal properties, either in small or large proportion. Different part of a plant often contains a quite different active ingredients, so that one part may be toxic and another one quite harmless ${ }^{26}$. The useful part of $I$. reniformis comprises of leaves and root $^{23}$.

\section{Ethno medicinal Uses}

A decoction of plant is said to act as deobstruent, diuretic; useful in rheumatism, neuralgia, headache, anthelmintic; diseases of the kidney, the lungs, the uterus; good in pains, fevers urethral discharges, anemia and lucoderma.
Leaf juice is given in rat bites and snake bites. In epilepsy powder of leaves is sniffed up. Paste of the root used in swelling ${ }^{19,27,28}$. Root is also having diuretic and purgative property $^{29}$. Decoction of whole plant is taken internally to treat stomach problems ${ }^{30}$.

\section{Phytochemicals}

The therapeutic value of the plant depends on the active constituents present in the small or large quantity ${ }^{31}$. The secondary metabolites are the important substance responsible for the main medicinal properties in the crude drugs $^{32}$. Aqueous extract revealed the presence of amino acid, tannins (condensed and pseudotanins), flavonoids, terpenoids, cardiac glycosides carbohydrates and $\operatorname{starch}^{25,33}$. Methanolic extract revealed the presence of tannins, flavonoids, amino acids, carbohydrates ${ }^{32}$. Petroleum ether extract contain tannins, flavonoids, amino acids, carbohydrates and starch ${ }^{33}$. Hydroalcoholic extract contain number of phytoconstituents such as tannins, phenols, carbohydrate, triterpenoids, reducing sugar, steroids, starch and flavonoids ${ }^{34}$. Ethanolic extract of plant showed the presence of tannins, flavonoids, phenolic compounds, terpenoids, steroids and carbohydrates. GC-MS analysis of the ethanolic extract of plant showed the presence of phytoconstituents sec-Butyl nitrite, 1,3,4,5-Tetrahydroxy-cyclohexanecarboxylic acid, (-)-Loliolide, Pluchidiol, 2,6,10-Trimethyl, 14-ethylene14-pentadecne, 2-Pentadecanone, 6,10,14-trimethyl-,nHexadecanoic acid, Hexadecanoic acid, ethyl ester, 2Hexadecen-1-ol, 3,7,11,15-Tetramethyl-, [R-[R*,R*(E)]]-, Ethyl(9Z,12Z)-9,12-Octadecadienoate, 9,12Octadecadienoic acid(9Z,12Z)-, Ethyl ester, Octadecanoic acid, S-[2-[N,N-Dimethyl amino] ethyl]N,Ndimethylcarbamoyl thiocarbohydroximate, Chloromethyl 5 -chloroundecanoate, Ethyl icosanoate, $\alpha$-Tocopherol- $\beta$ D-mannoside, Stigmasterol and Neophytadiene ${ }^{35}$.

\section{Pharmacology}

\section{Antioxidant activity}

Babu A. V. et al studied biological activities of different solvent extracts. Hexane, ethyl acetate, methanol and aqueous methanol extracts of $I$. reniformis were examined for antioxidant activity. Antioxidant property of the extracts were studied by DPPH (1,1-Diphenyl-2Picrylhydrozyl) radical scavenging activity method and superoxide radical scavenging activity method. Methanol extract exhibited better antioxidant effect than other extracts DPPH radical scavenging method. Methanol and hexane extracts exhibited $\alpha$-amylase inhibitory activity. Ethyl acetate extract showed cytotoxicity in brine shrimp lethality assay. The present study revealed that the extracts of ethyl acetate and methanol were found to be promising in biological activities. Methanol extract might be useful for antioxidant activity with minimal toxicity ${ }^{36}$.

\section{Antihypertensive}

Qaiser Jabeen and Naveed Aslam investigated hypotensive, angiotensin converting enzyme (ACE) inhibitory and diuretic activities of the aqueous-methanol (30:70) extract of the dried aerial parts of I. reniformis in rats. The extract produced fall in mean arterial blood pressure of the anaesthetised rats. Extract was found to 
have serum ACE inhibitory activity. The extract also significantly increased the volume and urinary $\mathrm{Na}^{+}$ excretion in rats. The study concludes that the extract of $I$. reniformis has hypotensive, ACE inhibitory and diuretic activities which provide the scientific justification for the traditional uses of the plant as cardioprotective, antihypertensive and diuretic remedy ${ }^{37}$. Natarajan P. et al studied effect of hydroalcoholic extract of whole plant $I$. reniformis on isoproterenol induced myocardial infraction in rat. The hydroalcoholic extract prevented isoproterenol induced increase in lipid peroxidation and increased the activities of antioxidant enzymes. The extract produced significant recovery of heart from isoproterenol induced myocardial ischemic injury. The result indicated the antioxidant, antilipid, peroxidative and anti-ischemic activity of I. reniformis was justified in the treatment of ischemic heart diseases in albino rats ${ }^{34}$.

\section{Antipyretic}

Indumathy S. et al screened the Anti-pyretic activity of ethanolic extract of $M$. emarginata in rat. The extract did not produce any toxic effect at the dose of $2 \mathrm{~g} / \mathrm{kg} .1 / 10^{\text {th }}$ dose of acute toxicity used for the study of antipyretic activity. The extract at the dose of $200 \mathrm{mg} / \mathrm{kg}$ i.p. possessed antipyretic activity as compare to standard drug paracetamol $150 \mathrm{mg} / \mathrm{kg}$ i.p. in albino rats ${ }^{29}$.

\section{Arthritis}

Purushoth Prabhu T. et al evaluated the effect of ethanolic and ethylacetate extract of I. reniformis on Freund's adjuvant induced arthritis. Extracts significantly reduces the paw thickness at the end of 21 days treatment. In acute phase inflammation both of them show the potency and in chronic phase alcoholic extract exhibit more potency than the ethyl acetate extract. At the end of study alcoholic extract shows more pronounce effect as compared with ethyl acetate extract ${ }^{38}$.

\section{Analgesic and anti-inflammatory}

Priya P. et al evaluated the ethanolic extract of the leaves of $I$. reniformis obtained by soxhlet extraction for analgesic action induced by acetic acid and tail immersion method in mice. The ethanolic extract in doses of 200 $\mathrm{mg} / \mathrm{kg}$ of body weight were evaluated for central analgesic activity by acetic acid induced writhing and tail immersion model in mice respectively. The ethanolic extract of the leaves of $I$. reniformis significantly reduced the writhing count. In tail immersion model, the ethanolic extract of the leaves significantly increase the reaction time $^{39}$. Purushoth Prabhu T. et al screened the antiinflammatory, antiarthritic and analgesic activity of ethanolic extract of whole plant of $I$. reniformis in experimental animal models. Ethanolic extract of whole plant was studied for its anti inflammatory activity using carrageenan induced rat paw oedema animal model, antiarthritis activity using complete Freund's adjuvant model and analgesic activity at the same dose level using hot plate analgesia in mice. The Percentage inhibition with indomethacin and ethanolic extract of whole plant in the carrageenan induced paw oedema was calculated. The results indicated that treatment of adjuvant induced arthritic rats with extract improves $\mathrm{ESR}, \mathrm{Hb}$ value and also restores body weight. Significant inhibitory effect was observed with extract on FCA induced paw oedema throughout the study. In tail flick method the extract showed delayed reaction time. The ethanolic extract possesses anti-inflammatory, antiarthritis and analgesic activity $^{40}$.

\section{Antidiabetic}

Rajiv Gandhi G. et al investigated the antidiabetic property of I. reniformis plant in streptozotocin induced diabetic rats. The dose dependent effects of 28 days oral treatment with methanol extract from the plant of $I$. reniformis on blood glucose level, body weight, insulin, total hemoglobin, glycosylated haemoglobin (HbA1C), total protein, serum urea, serum creatinine and carbohydrate metabolizing enzymes were evaluated in streptozotocin induced diabetic rats. Increase in body weight, insulin and protein level was observed in diabetic rats treated with $I$. reniformis. Treatment with $I$. reniformis resulted in a significant reduction of $\mathrm{HbA1C}$ and an increase in total hemoglobin level. The activities of carbohydrate metabolizing enzymes such as hexokinase were significantly increased whereas glucose6-phosphatase, fructose-1, 6-bisphosphatase were significantly decreased by the administration of $I$. reniformis in diabetic rats. Histology of diabetic rats treated with I. reniformis showed the pancreatic cells regeneration. These findings suggest that $I$. reniformis has potent antidiabetic activity in streptozotocin induced diabetic rats ${ }^{41}$.

\section{Antibacterial}

Elumalai E.K. et al studied the Antibacterial activity of various leaf extracts of $I$. reniformis. The antibacterial activity of leaf extracts of $I$. reniformis were evaluated by agar well diffusion method against four selected bacterial species. The methanol extract was more effective against Bacillus cereus and Escherichia coli, whereas aqueous extract was more effective against Staphylococcus aureus and Pseudomonas aeruginosa. The results in the present study suggest that $I$. reniformis leaf can be used in treating diseases caused by the tested organism ${ }^{34}$.

\section{Nephroprotective}

Nephrotoxicity is a common event, which can cause significant morbidity and can be easily overlooked. Cisplatin is a highly effective antineoplastic used against a wide variety of cancers and considered more common cause for nephrotoxicity. A large number of herbs have traditionally been used to treat drug or toxin-induced renal diseases. Sudhavani V. et al studied a similar attempt in that direction and evaluated the nephroprotector and antioxidant activity of $I$. reniformis against cisplatin induced nephrotoxicity. Ethanolic extract of the herb when administered at doses of $250 \mathrm{mg} / \mathrm{kg}$, p. o. to the preventive and curative groups, showed the decrease in elevation of blood urea nitrogen, serum creatinine, serum total proteins, urinary urea, urinary creatinine and urinary total proteins induced by administration of cisplatin. Thus, both groups showed significant protection against cisplatin induced nephrotoxicity in rats. Herb extract has also offered significant protection against oxidative stress 
induced by cisplatin, as noted by increase in superoxide dismutase, catalase, reduced glutathione along with decrease in lipid peroxidation levels were observed. So, the present work provides a scientific evidence for the nephroprotector activity of $I$. reniformis as claimed in indigenous system of medicine ${ }^{42}$.

\section{Anticancer activity}

Purushoth Prabhu T. et al investigated anticancer activity of $I$. reniformis against human cervical and breast carcinoma. The study was designed to evaluate the in vitro anticancer activity of $I$. reniformis. The different solvent fraction of whole plant $I$. reniformis was subjected for activity. The ethyl acetate fraction of whole plant was found to be cytotoxic against human cervical carcinoma Hela cell lines and human breast carcinoma MCF cell lines ${ }^{43}$.

\section{Marketed Preparation}

I. reniformis fresh plant juice used in Ayurvedic preparation Krumikuthar Rasa; it is used as anthelmintic ${ }^{44}$

\section{CONCLUSION}

Literature review of $I$. reniformis plant showed different pharmacological activity in animal which support the traditionally claimed medicinal activity. It can be concluded that $I$. reniformis seems to be promising plant in various activities hypertension, arthritis, analgesic, antibacterial and nephroprotective activity. This activity may be due to presence of phytoconstituents flavonoids, terpenoids, cardiac glycosides, tannins. Further studies are necessary for chemical characterisation of the active principles and for more extensive biological evaluation. $I$. reniformis is also studied for its different pharmacological activity but still traditionally claimed therapeutic potential of plant is not studied. Hence I. reniformis can be further explored for the study of traditionally claimed unexplored activities as well as isolation and identification of active constituents and to confirm exact mechanism of action.

\section{REFERENCES}

1. Crag GM, Newman DJ and Snader KM. Natural products in drug discovery and development. J Natural Product 1997; 60: 52-54. http://dx.doi.org/10.1021/np9604893

2. Shu YZ. Recent natural products based drug development, A pharmaceutical industries perspectives. J Natural product 1998; 61: 1053. http://dx.doi.org/10.1021/np9800102

3. Panda Ashok Kumar. Medicinal plants in Sikkim. Regional research institute (Ayurveda), Tadong, Gangtok Sikkim; 1-5.

4. Cordel GA. Biodiversity and drugs discovery-a symbiotic relationship. Phytochem 2000; 55: 463-480. http://dx.doi.org/10.1016/S0031-9422(00)00230-2

5. Farnsworth NR, Olayiwola A, Audrey SB, Djaja DS, Zhengang G. Medicinal plants in therapy. Bulletin of the World Health Organisation 1985; 63 (6): 965-981.

6. Prabhakaran M, Chandrakala $\mathrm{N}$ and Panneerselvam A. Antimicrobial activity of Indigofera glandulosa (wild). Asian J Plant Sci. Res 2011; 1(2): 18-25.

7. Ansari SH. Essential of Pharmacognosy. $2^{\text {nd }}$ Ed. India: Birla publication, New Delhi; 2007. p. 01-07.

8. Jeeva S, Kiruba S, Mishra BP. Weeds of Kanyakumari district and their value in rural life. Indian J of Traditional Knowledge 2006; 5(4): 501-509.

9. Kingston DGI. Tublin-interactive natural products as anticancer agents. J Natural Product 2009; 72: 507-515. http://dx.doi.org $/ 10.1021 / \mathrm{np} 800568 \mathrm{j}$
10. Patil HM and Bhaskar VV. Medicinal uses of plants by tribal medicine men of Nandurbar district in Maharashtra. Explore research Article 2006; 5(2): 125-144.

11. Ashalata DK, Khan ML, Tripathi RS. Ethnomedicinal plants in the sacred groves of Manipur. Indian J. of Traditional Knowledge 2005; 4(1): 21-32.

12. Agharkar SP. Medicinal plants of Bombay. India: Presidency scientific publications; 1991. p. 48-49.

13. Ruchika Nanda, Singh H. Amalgamation of Ayurveda with allopathy: a synergistic approach for healthy society. International J of green Pharmacy 2013: 173-176.

14. Verma S, Singh SP. Current and future status of herbal medicines. Veterinary World 2008; 1(11): 347-350. http://dx.doi.org/10.5455/ vetworld.2008.347-350

15. Jyotsna B, Zafar YK. Comparative evaluation of the efficacy and side effects of imipramine, sertraline and Ayurvedic formulation in patients of depression. J clinical and diagnostic research 2012;6(2): 220-225.

16. Jain S, Tandon PN. Ayurvedic medicine and Indian literature on epilepsy. Neurology Asia 2004; 9 Suppl 1: 57-58.

17. Saxena MJ. Relevance the herbs in improving health index of livestock animals. National veterinary Medical Association Conference. Ibadan; 2003.

18. Kokate CK, Purohit AP, Gokhale SB. Pharmacognosy. $48^{\text {th }}$ ed India: Nirali Prakashan, Pune; 2013. p. 1.5.

19. Kirtkar KR, Basu BD. Indian medicinal plants. $2^{\text {nd }}$ ed. India: Lalit Mohan Basu, Allahabad; 1935. p. 1702.

20. Shah CS, Sukkawala VM, Chavan AR, Pharmacognostic study of Ipomea reniformis and comparison with Centalla asiatica Linn. Science communication, National Institute of Science Communication and Information Resources; 1962. p. 22.

21. http//:www.stuartexchange.org/kupit-kupit.html

22. http//:www.convovilaceae.myspecies.info/category/convolvulaceae.

23. Nadkarni KM. Indian Meteria Medica. $3^{\text {rd }}$ ed. India: Bombay Popular Prakashan, Bombay; 1954. p. 690.

24. Bhatt MK, Dholwani KK, Saluja AK. Ipomea reniformis: a scientific review. International J. of Pharmacy and Pharmaceutical Sciences 2010; 2 (4): 2-4.

25. Usnale SV, Garad SV, Panchal CV, Poul BN, Dudhamal SS, Thakare CV. Pharmacognostic studies on Ipomea reniformis chois. International J Pharma and Clin research 2009; 1(2): 65-67.

26. Wyk Ben Erik, Van Wink Michael. Medicinal plants of the World. $3^{\text {rd }}$ Ed. Malaysia: Times Editions; 2004. p. 16-20.

27. Chopra RN, Chopra IC, Handa KL, Kapur LD. Indigenous Drugs of India. $2^{\text {nd }}$ ed., India: Academic Publishers, Calcutta; 1982. p. 511.

28. Khare CP. Indian medicinal plants- an illustrated dictionary. Springer; 2007. p. 335

29. Indumathy $\mathrm{S}$, Gausunnisha $\mathrm{T}$, Rajlakshmi $\mathrm{R}$, Roselin $\mathrm{A}$, Thamizharasy P, Arul Anandraj CA. Antipyretic activity of ethanolic extract of Merremia emarginata (Burm. F) hallier F. in rat. International J of Pharm Applications 2011; 2(4): 258-61.

30. Chellaiah M, Muniappan A, Nagappan R et al Medicinal plants used by traditional healers in Kancheepurum district of Tamilnadu, India $\mathrm{J}$ of ethno biology and ethno medicine 2006; 2: 43 http://dx.doi.org/10.1186/1746-4269-2-43

31. Sardana S, Sharma OP. Fundamentals of pharmacognosy. $1^{\text {st }}$ ed. India: Birla publication, Delhi; 2009-10. p. 40-42.

32. Rangari VD. Traditional drug of India, Pharmacognosy and phytochemistry. $2^{\text {nd }}$ ed. Vol II. India: Career Publication, Nasik; 2009. p. 01-04.

33. Elumalai EK, Ramchandran M, Thirumalai T, Vinothkumar P. Antibacterial activity of various leaf extracts of Merremia emarginata. Asian Pac J Trop Biomed 2011; 1(5): 406-408. http://dx.doi.org/10.1016/S2221-1691(11)60089-0

34. Natrajan P, Jaspher SS, Thangathirupathi A, Solairaj P, Hari Dhas Effect of Merremia emarginata Burn. F. on Isoproterenol Induced myocardial Infraction in rat. International $\mathbf{J}$ of Biologicals and Pharm Res 2014; 5(1): 8-15.

35. Purushottam PT, Panneerselvam P, Suresh R, Sevalkumari S, Shantha A. Phytochemical Analysis of ethanolic extract of Merremia emaraginata Burm. F by GC-MS. Res J of pharmaceutical biological and chemical sciences 2012; 3(4): 507.

36. Babu AV, Rao RSC, Kumar KG, Babu BH, Satyanarayana PVV. Biological activity of Merremia emarginata crude extracts in different solvents. Res J of Medicinal Plant 2009: 1-6.

37. Quiser J and Naveed A. Hypotensive, angiotensin converting enzyme inhibitory and Diuretic activities of the aqueous-methanaol 
extract of Ipomea reniformis. Iranian J of Pharmceutical Res 2013; 12(4): 769-776

38. Purushoth PT, Pannerselvam P, Sevalkumari S, Vijaykumar R, Sivraman D. Effect of ethanolic and ethylacetate extract of Merremia emarginata (Burm.F) in rheumatoid arthritis. Int. Res. J. Pharm 2012; 3(9): 264-268.

39. Priya P, Arul Anandraj CN, Gausunnisha T, Rajlakshmi R, Roselin A, Grandhi U. Study of analgesic activity of Merremia emarginata (Burm. F) Hallier F. Int J Pharm Bio Sci 2012; 2 (3): 209-302.

40. Purushoth PT, Pannerselvam P, Vijaykumar R, Clement AW, Balasubramanian S. Anti-inflammatory, antiarthritis and analgesic effect of ethanolic extract of whole plant of Merremia emarginata Burm.F. Central European J Experimental Bio 2012; 1(3): 94-99.

41. Gandhi RG, Sasikumar P. Antidiabetic effect of Merremia emarginata Burm. F. in streptozocin induced diabetic rats. Asian Pac J Trop Biomed 2012; 2(4): 281-286. http://dx.doi.org/ $10.1016 / \mathrm{S} 2221-1691(12) 60023-9$
42. Sudhavani V, Chinnikrishnaiah V, Raghu MV, Raghvendra HG, Ranganayakulu D. Nephroprotective activity of Merremia emarginata burn against cisplatin induced nephrotoxic rats. Journal of Advances in Drug Research 2010; 1(1): 27-34.

43. Purushoth PT, Panneerselvam P, Selvakumari S, Udhumansha Ubaidulla, Shantha A. Anticancer activity of Merremia emarginata (Burm. F) against human cervical and breast carcinoma. Int $\mathrm{J}$ of Res and development in pharmacy and life sci 2012; 1(4): 189-192.

44. http://www.sdlindia.com/show_products.php?id=82andht $=10$

Cite this article as:

Thakare C. V., Upasani C. D., Poul B. N., Patil S. S., Usnale S. V. Ipomea reniformis: A review of its ethnomedicinal uses, phytochemistry and pharmacology. Int. J. Res. Ayurveda Pharm. 2014;5(6):657-661 http://dx.doi.org/10.7897/2277-4343.056134 